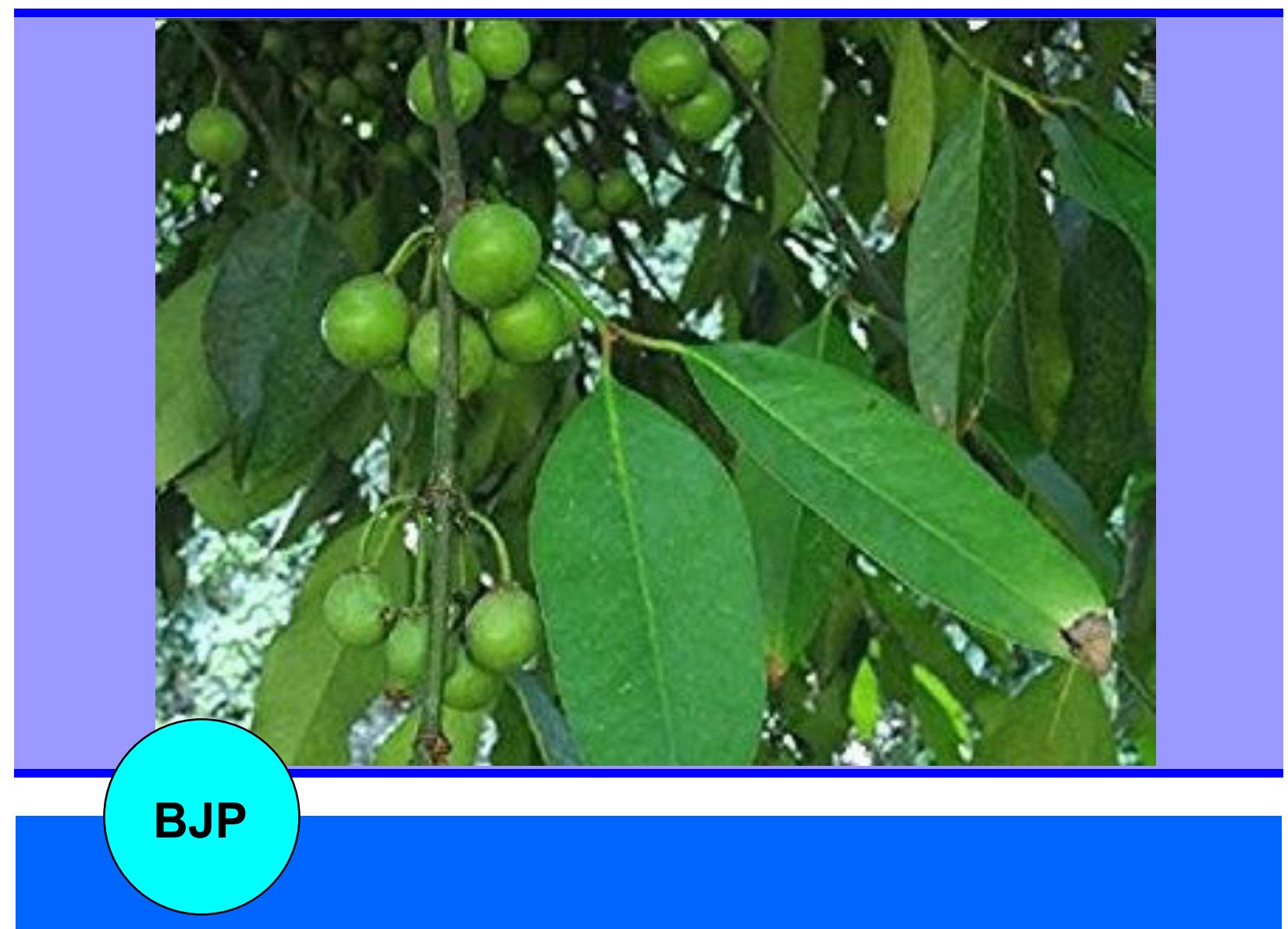

Bangladesh Journal of Pharmacology

Research Article

Cardioprotective activity of fruit of Garcinia pedunculata on isoprenaline-induced myocardial infarction in rat 
Abstracted/indexed in Academic Search Complete, Asia Journals Online, Bangladesh Journals Online, Biological Abstracts, BIOSIS Previews, CAB Abstracts, Current Abstracts, Directory of Open Access Journals, EMBASE/Excerpta Medica, Google Scholar, HINARI (WHO), International Pharmaceutical Abstracts, Open J-gate, Science Citation Index Expanded, SCOPUS and Social Sciences Citation Index;

ISSN: $1991-0088$

\title{
Cardioprotective activity of fruit of Garcinia pedunculata on isoprenaline-induced myocardial infarction in rat
}

\author{
Ravi Mundugaru', Padmaja Udaykumar², Sivanesan Senthilkumar3 and Sudhakara Bhat ${ }^{1}$ \\ ${ }^{1}$ Department of Pharmacology and Toxicology, SDM Centre for Research in Ayurveda and Allied Sciences, \\ Udupi 574 118, India; ${ }^{2}$ Department of Pharmacology Father Muller Medical College, Mangalore 575 002, India; \\ ${ }^{3}$ Department of Research and Development, Saveetha University, Thandalam, Chennai 602105 , India.
}

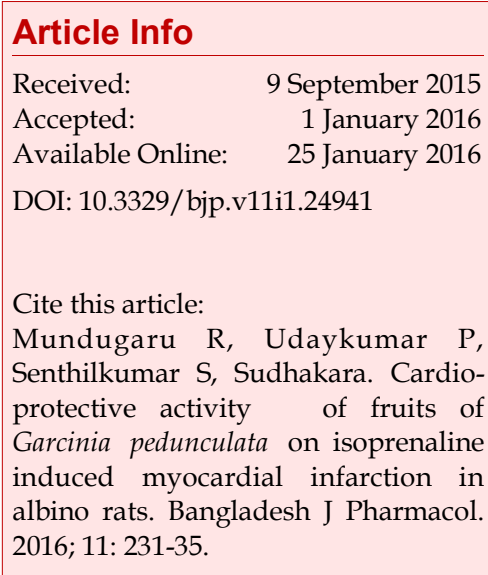

\begin{abstract}
The present study reveals the protective effect of Garcinia pedunculata aqueous fruit extract in isoprenaline-induced myocardial infarction in Wistar rats. Isoprenaline $(200 \mathrm{mg} / \mathrm{kg}$ ) administration subcutaneous once daily for two consecutive days significantly $(\mathrm{p}<0.01)$ increased the CK-MB, AST, ALT, ALP activity and CRP $(\mathrm{p}<0.05)$ levels. Pretreatment with extract $(400 \mathrm{mg} / \mathrm{kg})$ orally for 14 consecutive days significantly ameliorated the effect of isoprenaline by reducing the activity of CK-MB and the levels of ALP, SGPT respectively. No significant changes were seen in the case of SGOT activity and CRP levels. Severe necrotic lesions in the myocardial tissue were observed in the isoprenaline-treated group. In extract-treated group, mild degenerative changes of myocardial tissues to nearly normal cytoarchitecture were seen. The results indicate the cardioprotective effect of G. pedunculata against isoprenaline- induced myocardial infarction rat model.
\end{abstract}

\section{Introduction}

Myocardial infarction is the acute ischemic condition where profound necrosis of myocardial tissue occurs. This mainly results of imbalance between coronary blood supply and myocardial oxygen demand (de Bono et al., 1992). Isoprenaline is a synthetic catecholamine acts as a $\beta$ adrenergic agonist. It has been reported to produce myocardial infarction in higher dose (Jordan et al., 1999; Panda and Naik, 2009). Isoprenaline undergoes auto-oxidation and generate highly cytotoxic free radicals. These free radicals stimulate per-oxidation of membrane phospholipids causing severe damage to myocardial membrane. Subsequently, the inflammation event takes place with infiltration of neutrophils into the infarcted area where it can promote myocardial cell damage through the release of proteolytic enzymes. It intern produces cytotoxic reactive oxygen species (Kannan and Quine, 2013). Thus, the model is used as a novel method to produce myocardial infarction in experimental animals.
Amlavetasa Garcinia pedunculata is a medicinal herb that belongs to the family Clusiaceae. Tribal people of Assam region were widely using the dried fruits of the plant as cardiotonic along with their diet (Comalada et al., 2005). It has been reported that the dried fruits of GP are used for asthma, cough, bronchitis and fever (Jayaprakasha et al., 2006). The phytochemical analysis has shown the dried fruit rinds and pericarp contains (-) hydroxy citric acid, benzophenones, pedenculol, garcinol and cambogin (Kagyung et al., 2010). It has been screened for its anti-inflammatory, in vitro anti-oxidant and hepatoprotective activity (Patiri and Borah, 2007; Ravi Mundugaru et al., 2014). At present, there is an increased attention on phytochemicals and polyphenols such as alkaloids, flavonoids, xanthenes derived from different plant species. These chemicals possess excellent anti-oxidant properties and have potential therapeutic values in prevention and management of cardiovascular disease (Sahu et al., 1989).

As there is no documented experimental basis for its 
use as a cardiotonic activity, the present study has been carried out to elucidate cardioprotective activity of aqueous extract of G. pedunculata in isoprenalineinduced myocardial infarction model.

\section{Materials and Methods \\ Plant material and extract preparation}

Fruits of G. pedunculata were collected from Assam region, India with the help of a botanist during March of 2012. It was authenticated in Pharmacognosy Laboratory, SDM Centre for Research in Ayurveda and Allied Sciences, Udupi. The voucher specimen (No. 13100501) has been deposited for further future reference. The powder of fruits of G. pedunculata was prepared in the Pharmacy attached to SDM College Ayurveda, Udupi, from authenticated plant material. The powder obtained from a single batch was used throughout the experimental study. Two fifty grams of the fruit powder of G. pedunculata was soaked in 2L of distilled water for 24 hours; it was filtered and concentrated in a water bath. The concentrated extract of G. pedunculata was used for the isoprenaline-induced cardioprotective activity.

\section{Experimental animals}

Male Wistar albino rats weighing 180-220 g were obtained from animal house attached to SDM Centre for Research in Ayurveda and Allied Sciences, Udupi. They were fed with standard diet and water ad libitum. The animals were housed in a controlled environment with 12:12 hours light and dark cycle, temperature of $25^{\circ} \mathrm{C}$ and relative humidity $50 \%$. The experimental animals were acclimatized for two weeks in the laboratory condition before the experiment. The experiments were carried out in accordance with the guidelines of institutional ethical committee under the reference number SDMCRA/IAEC/2012-13DGM 03ab.

\section{Chemicals}

Isoprenaline was purchased from Sigma Chemicals USA (product code- 101128695).

\section{Acute oral toxicity test}

The acute oral toxicity study was carried out as per OECD guidelines 425 using AOT software. The aqueous extract of fruits of G. pedunculata was made into a suspension in $0.5 \%$ gum acacia and dosed in the following order 175, 550 and $2000 \mathrm{mg} / \mathrm{kg}$ body weight. After the dosing, the animals were observed for 14 days for mortality. The LD 50 was determined by using AOT software.

\section{Induction of myocardial infarction}

Isoprenaline was dissolved in normal saline and injected subcutaneously at a dose of $200 \mathrm{mg} / \mathrm{kg}$ body weight once daily for 2-consecutive days (Priscilla and Prince, 2009; Kumaran and Prince, 2010).

\section{Experimental design}

Rats were randomly divided into three groups of six rats each. Group I received $0.5 \%$ gum acacia for 14 consecutive days and served as normal control group. Group II rats received $0.5 \%$ gum acacia for 14 consecutive days and in addition received isoprenaline $200 \mathrm{mg} /$ $\mathrm{kg}$, subcutaneously at an interval of 24 hours. Group III rats were pre-treated with $400 \mathrm{mg} / \mathrm{kg}$ of extract for a period of 14 consecutive days and in addition received isoprenaline $200 \mathrm{mg} / \mathrm{kg}$, subcutaneously on $14^{\text {th }}$ and $15^{\text {th }}$ day at an interval of 24 hours.

Twenty-four hours after the last dose of isoprenaline, animals were anesthetized and blood samples were collected from retro-orbital puncture for estimation of biochemical parameters such as CK-MB in serum was that was determined using CK-MB diagnostic kit and CRP was measured using a specific immunoassay kit (Immunospec Corporation, USA). The serum biochemical markers such as AST, ALT and ALP measured according to standard methods (Bradly et al., 1972; Wilkinson et al., 1969). Rats were then sacrificed under deep anesthesia and the heart was rapidly isolated washed with ice-cold saline. The tissue was then transferred to $10 \%$ formalin for histological examination. The tissue was embedded in paraffin. The section was cut at $5 \mu \mathrm{m}$ thickness and stained with hematoxyline-eosin stain and mounted in diphenyl xyline. The histopathological changes of heart tissue were observed under a compound microscope and their micro-photographs were taken (Bancroft and Gamble, 2002).

\section{Statistical analysis}

The experimental data were expressed as mean \pm SEM. Statistical analysis was carried out by one-way analysis of variance followed by Dennett multiple t-test. A level for $\mathrm{p}<0.05$ was considered to be statistically significant.

\section{Results}

In acute oral toxicity study in any dose up to 2,000 mg/ $\mathrm{kg}$ of aqueous extract of fruits of the plant $G$. pedunculata did not produce any mortality. This indicates that $\mathrm{LD}_{50}$ is much more than $2,000 \mathrm{mg} / \mathrm{kg}$ and hence $1 / 5^{\text {th }}$ of the dose was selected for the present cardioprotective study.

A significant elevation in the serum CK-MB, SGOT, SGPT, ALP activity and C-reactive protein levels were observed in isoprenaline-treated myocardial infarcted rats as compared to Group I control rats (Table I). The extract pre-treated group significantly reduced the activity of serum biomarkers such as CK-MB, SGPT and ALP and caused mild to moderated reduction of SGOT 
Table I

Effects of fruit extract of G. pedunculata on biochemical parameters

\begin{tabular}{|lrrrrrr|r|}
\hline Group & \multicolumn{1}{c}{ Dose } & $\begin{array}{c}\text { Serum SGOT } \\
(\mathrm{IU} / \mathrm{dL})\end{array}$ & $\begin{array}{c}\text { Serum SGPT } \\
(\mathrm{IU} / \mathrm{dL})\end{array}$ & $\begin{array}{c}\text { Serum ALP } \\
(\mathrm{IU} / \mathrm{dL})\end{array}$ & $\begin{array}{c}\text { Serum CRP } \\
(\mathrm{mg} / \mathrm{L})\end{array}$ & CK-MB (U/L) \\
\hline Normal control & $5 \mathrm{~mL} / \mathrm{kg}$ & $130.0 \pm 6.8$ & $40.7 \pm 4.4$ & $185.0 \pm 21.1$ & $0.7 \pm 0.0$ & $79.0 \pm 5.5$ \\
Isoprenaline control & $200 \mathrm{mg} / \mathrm{kg}$ & $252.8 \pm 13.3^{\mathrm{a}}$ & $262.7 \pm 39.4^{\mathrm{a}}$ & $483.2 \pm 43.4^{\mathrm{a}}$ & $1.2 \pm 0.2^{\mathrm{a}}$ & $325.0 \pm 48.7 \mathrm{a}$ \\
Extract + Isoprenaline & $400 \mathrm{mg} / \mathrm{kg}$ & $248.6 \pm 23.0$ & $107.0 \pm 8.7^{\mathrm{b}}$ & $254.7 \pm 36.2^{\mathrm{b}}$ & $0.9 \pm 0.1$ & $92.0 \pm 2.5^{\mathrm{b}}$ \\
\hline
\end{tabular}

Data expressed in Mean \pm SEM, a $<<0.01$ in comparison to normal control group, ${ }^{b} \mathrm{p}<0.01$ in comparison to isoprenaline control

activity and CRP levels in serum (Table I).

\section{Histological examination of heart tissue}

Microscopic examination of the section of heart from different groups was carried out to assess the impact of isoprenaline injection on cardiac cytoarchitecture and its modulation by test drug administration.

Sections of heart from normal control rats exhibited normal cytoarchitecture. The myofibrillar structure was normal with striations, branching and continuity with adjacent myofibrils.

Examination of sections of heart from isoprenaline group exhibited remarkable changes in the cytoarchitecture. In most of the rats moderate to severe necrotic lesions were found especially in the apical region. The basal region was not affected to great extent. In the area surrounding this region myocarditis, interstitial edema and focal cell infiltration were observed. Loss of myocardial fibres was observed in some areas. Hemorrhage and fatty changes were observed in some sections. Severe necrotic lesions were observed in all the rats in this group (Figure 1).

In G. pedunculata extract-treated isoprenaline injected group, the severity of the degenerative changes was found to be moderate and less in comparison to the control isoprenaline group. Moderate necrosis with cell infiltration was observed in sections from two rats. Mild to moderate necrosis and degenerative changes in the form myocarditis and fatty changes were observed in sections from the remaining rats.

\section{Discussion}

In the present study, there is a significant elevation in serum CK-MB, ALT, AST and ALP levels in isoprenaline treated group. Pre-treatment with G. pedunculata extract for 14 days showed a marked decrease in the elevated serum biomarkers. This suggests the test drug has the potential to inhibit free radical generation and subsequent cell damage. The earlier report suggests that the test drug has strong anti-oxidant potential. This might be the possible mechanism of the protective outcome of the present study.

Subsequently after myocardial infarction caused by isoprenaline inflammatory process involved in the myocardial tissue damage and cellular necrosis. It is reported that the infarcted area undergoes local necrosis and myocyte apoptosis resulting in complementary activation, free radical generation and accumulation of cellular debris. This is followed by infiltration of neutrophils and macrophages into the infarcted area, where they can promote myocardial cell damage by release of proteolytic enzymes and cytokines. Pretreatment with extract showed a marked decrease in the serum levels of CRP. It is also reported that extract has good anti-inflammatory activity (Ravi Mundugaru et al., 2014).

Histological examination of sections of heart from isoprenaline treated group exhibited remarkable changes in the cytoarchitecture. In most of the rats moderate to severe necrotic lesions were found especially in the apical region than basal. In the area surrounding this region myocarditis interstitial edema, focal cell infiltration, hemorrhages and fatty changes were observed. Extract-treated group showed maximum protective effect by reduced histological changes as compared to isoprenaline-treated myocardial infarcted rats.

\section{Conclusion}

Aqueous extract of fruits of G. pedunculata protected experimentally induced myocardial infarction in rats as revealed by the amelioration of histological changes and biochemical and inflammatory markers of cardiac tissue damage.

\section{Acknowledgement}

Authors are highly grateful to revered President Dr. D. Veerendra Heggade for the constant support, and Dr. B. Yashoverma, Secretary, SDM Educational Society for the guidance. We thank the Registrar, Research Director and Dean, Saveetha University, Chennai for their constant motivation to carry out the research activities.

\section{References}

Bradly DW, Maynard JE, Emery G, Webster H. Transaminase activities in serum of long-term hemodialysis patients. Clin 


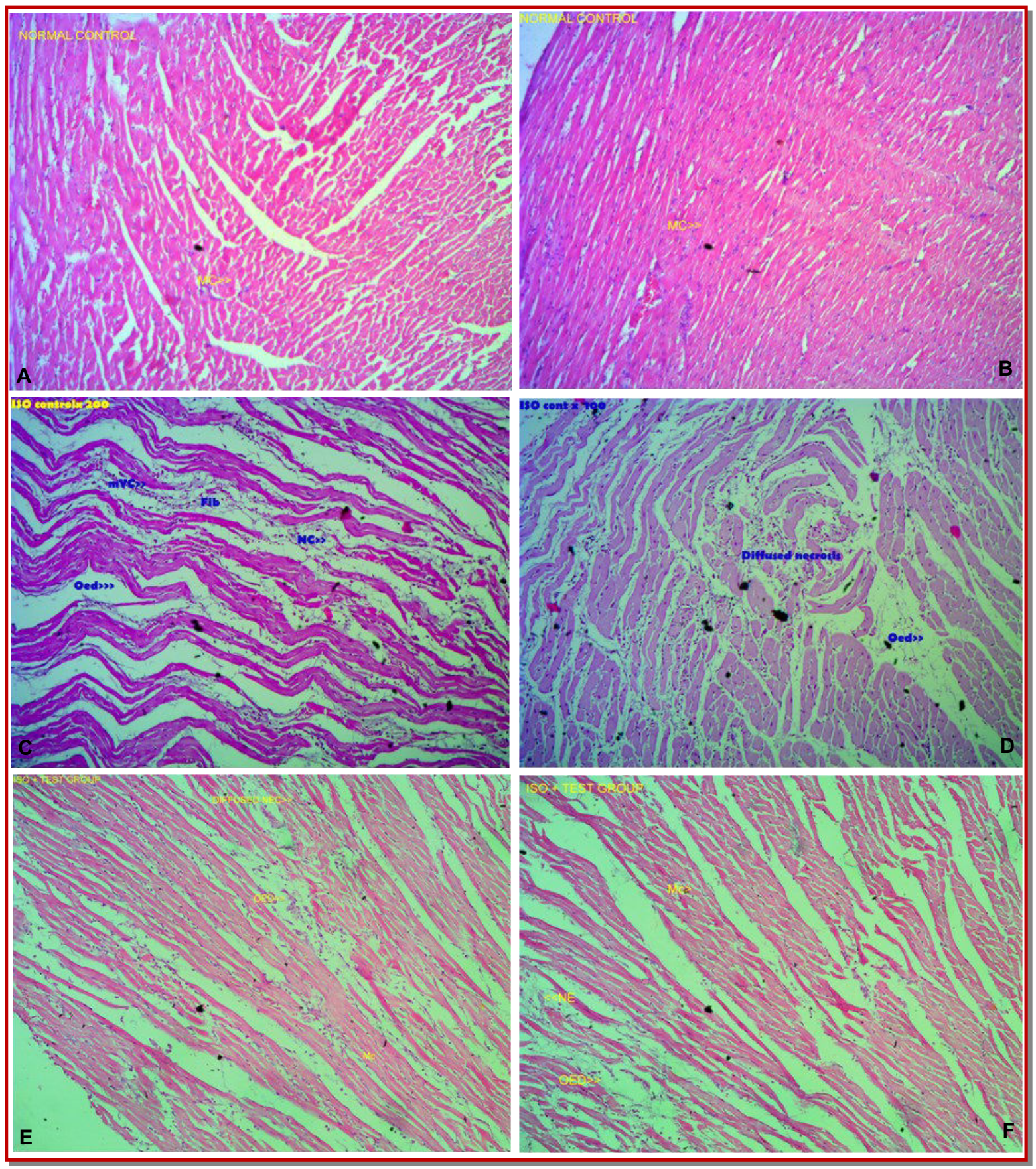

Figure 1 (A, B): Photomicrographs of representative heart sections from normal control group treated with gum acacia shows normal cytoarchitecture. Myocardium (MC); (C, D): Photomicrographs of representative heart sections from isoprenaline group shows moderate to severe necrotic lesions (NC), myocarditis interstitial edema (Oed), focal cell infiltration ( $\mathrm{Fc}$ ), hemorrhages (Hg) and fatty changes were observed; (E, F): Photomicrographs of representative heart sections from test drug + Isoprenaline injected rats shows mild moderate necrotic lesions (NEC) and myocardial interstitial edema (Oed). The test drug showed a maximum protective effect by reduced histological changes

Chem. 1972; 18: 1442.

Bancroft JD, Gamble M. Theory and practice of histological techniques. $5^{\text {th }}$ ed. Churchill Livingstone, 2002.

Comalada M, Camuesco D, Sierra S, Ballester I, Xaus J, Galvez $\mathrm{J}$, et al. In vivo quercitrin anti-inflammatory effect involves release of quercetin, which inhibits inflammation through down-regulation of the NF-kappa B pathway. Eur J Immunol. 2005; 35: 584-92.

Cusack MR, Marber MS, Lambiase PD, Bucknall CA, Redwood SR. Systemic inflammation in unstable angina is the result of myocardial necrosis. J Am Coll Cardiol. 2002; 39: 1917-23. 
de Bono DP, Simoons ML, Tijssen J, Arnold AE, Betriu A, Burgersdijk $C$, et al. Effect of early intravenous heparin on coronary patency, infarct size, and bleeding complications after alteplase thrombolysis: Results of a randomised double blind European Cooperative Study Group Trial. Br Heart J. 1992; 67: 122-28.

Jordan JE, Zhao ZQ, Vinten-Johansen J. The role of neutrophils in myocardial ischemia-reperfusion injury. Cardiovasc Res. 1999; 43: 860-78.

Kannan MM, Quine SD. Ellagic acid inhibits cardiac arrhythmias, hypertrophy and hyperlipidaemia during myocardial infarction in rats. Metabolism 2013; 62: 52-61.

Jayaprakasha GK, Negi PS, Jena BS. Anti-oxidative and antimutagenic activities of the extracts from the rinds of Garcinia pedunculata. Innov Food Sci Emerg Technol. 2006; 7: 246-50.

Kagyung R, Gajurel PR, Rethy P, Singh B. Ethnomedicinal plants used for gastrointestinal diseases by Adi tribes of Dehang-Debang biosphere reserve in Arunachal Pradesh. Indian J Tradit Knowl. 2010; 9: 496-501.

Kumaran KS, Prince PS. Caffeic acid protects rat heart mitochondria against isoproterenol-induced oxidative damage. Cell Stress Chaperon. 2010; 15: 791-806.

Patiri B, Borah A. Wild edible plants of Assam. 1st ed. Assam, The Director Forest Communication, Forest Department,
Assam, 2007.

Panda VS, Naik SR. Evaluation of cardioprotective activity of Ginkgo biloba and Ocimum sanctum in rodents. Altern Med Rev. 2009; 14: 161-71.

Priscilla DH, Prince PS. Cardioprotective effect of gallic acid on cardiac troponin-T, cardiac marker enzymes, lipid peroxidation products and anti-oxidants experimentally induced myocardial infarction in Wistar rats. Chem Biol Interact. 2009; 179: 118-24.

Ravi Mundugaru, Febin Joy, Shrinidhi R, Lipika Das, Sudhakara, Ravishankar B. Anti-inflammatory activity of aqueous extract of fruits of Garcinia pedunculata in experimental animals. Am J Pharma Tech Res. 2014: 4; 3.

Rathore N, Kale M, John S, Bhatnagar D. Lipid per-oxidation and anti-oxidant enzymes in isoproterenol-induced oxidative stress in rat erythrocytes. Indian J Physiol Pharmacol. 2000; 44: 161-66.

Sahu A, Das B, Chatterjee A. Polyisoprenylated benzophenones from Garcinia pedunculata. Phytochemistry 1989; 28: 1233-35.

Wilkinson J H, Boutwell J H, Winsten S. Evaluation of a new system for kinetic measurement of serum alkaline phosphatase. Clin Chem. 1969; 15: 487-95. 


\section{Your feedback about this paper}

1. Number of times you have read this paper 0

2. Quality of paper Click

3. Your comments

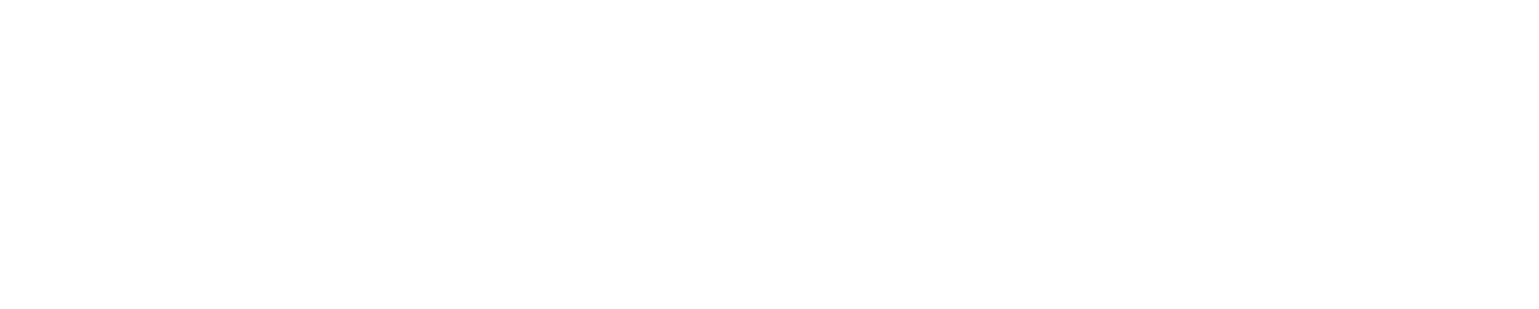

